\title{
Comparative study of the antihypertensive effects of hexane, chloroform and methanol fractions of essential oil of Alpinia zerumbet in rats Wistar
}

CUNHA, G.H.'; FECHINE, F.V.2; FROTA BEZERRA, F.A.2; MORAES, M.O.2, SILVEIRA, E.R. ${ }^{3}$; CANUTO, K.M.4; MORAES, M.E.A. ${ }^{2}$

1Universidade Federal do Ceará, Departamento de Enfermagem,Rua Alexandre Baraúna 1115, Rodolfo Teófilo, CEP: 60430-160, Fortaleza-Brasil. 2Universidade Federal do Ceará, Unidade de Farmacologia Clínica, Departamento de Fisiologia e Farmacologia, Rua Coronel Nunes de Melo 1127, Rodolfo Teófilo, CEP: 60430-270,

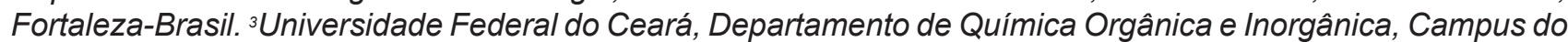
Pici, CEP: 60541-970, Fortaleza-Brasil. " Embrapa Agroindústria Tropical, Rua Dra. Sara Mesquita, 2270, Planalto Pici, CEP: 60511-110, Fortaleza, CE, Brazil. *Autor para correspondência: gilmaraholandaufc@yahoo.com.br

\begin{abstract}
The aim of this study was to characterize components of the EOAz and its hexane (HFEOAz), chloroform (CFEOAz) and methanol (MFEOAz) fractions, and its antihypertensive effect. EOAz was extracted from leaves by hydrodistillation. Aliquot was subjected to selective desorption with silica gel column and eluted with hexane, chloroform and methanol. The components of the EOAz and fractions were analyzed by gas chromatography coupled with mass spectrometry and nuclear magnetic resonance spectroscopy of hydrogen. Experiments of vascular reactivity were performed with isolated aortic rings of male Wistar rats. Antihypertensive effect was evaluated in hypertensive rats submitted to the inhibition of synthesis of nitric oxide. Blood pressure was measured indirectly by tail plethysmography. MFEOAz showed the lowest EC50 $(150.45 \mu \mathrm{g} / \mathrm{mL}), 1,8$-cineole $(27.81 \%)$ and terpinen-4-ol $(57.35 \%)$ as main components. Single administration by nasogastric tube of EOAz, fractions and captopril significantly reduced the blood pressure of hypertensive rats, when compared to animals of the negative control group with distilled water. In conclusion, the potency of the MFEOAz was higher than that of EOAz and other fractions. The antihypertensive effect of EOAz and fractions was similar, higher than the negative control and lower than that of captopril.
\end{abstract}

Keywords: Alpinia, phytotherapy, vasodilation, hypertension.

RESUMO: Estudo comparativo do efeito anti-hipertensivo das frações hexânixa, clorofórmica e metanólica do óleo essencial da Alpinia zerumbet. O objetivo deste estudo foi caracterizar os componentes do óleo essencial das folhas de Alpinia zerumbet (OEAz) e suas frações hexânica (FHOEAz), clorofórmica (FCOEAz) e metanólica (FMOEAz), e seu efeito anti-hipertensivo. OEAz foi extraído das folhas por hidrodestilação. Uma alíquota foi submetida à desadsorção seletiva com coluna de gel de sílica e eluída com hexano, clorofórmio e metanol. Os componentes do OEAz e fracções foram analisadas por cromatografia gasosa acoplada à detector de massa e por espectros de ressonância magnética nuclear de hidrogênio. Experimentos de reatividade vascular foram realizados com anéis aórticos isolados de ratos Wistar machos. Efeito anti-hipertensivo foi avaliado em ratos hipertensos submetidos à inibição da síntese de óxido nítrico. A pressão arterial foi medida indiretamente por pletismografia de cauda. FMOEAz mostrou a menor CE50 $(150,45 \mu \mathrm{g} / \mathrm{mL}), 1,8$-cineol $(27,81 \%)$ e terpinen-4-ol (57,35\%) como componentes principais. A administração em dose única por sonda nasogástrica de OEAz, frações e captopril reduziu significativamente a pressão arterial de ratos hipertensos, quando comparados aos animais do grupo controle negativo com água destilada. Em conclusão, a potência da FMOEAz foi maior que a do OEAz e outras frações. O efeito anti-hipertensivo de OEAz e frações foi semelhante, maior do que o controle negativo e menor do que o captopril.

Palavras-chave: Alpinia, fitoterapia, vasodilação, hipertensão.

Recebido para publicação em 20/03/2015

Aceito para publicação em 19/10/2015

10.1590/1983-084X/15_054

Rev. Bras. PI. Med., Campinas, v.18, n.1, p.113-124, 2016. 


\section{INTRODUCTION}

Hypertension is a multifactorial systemic chronic disorder through macrovascular and microvascular alterations at the functional and structural levels (Yannoutsos et al., 2014). High blood pressure may cause serious diseases such as heart failure, kidney failure and stroke (Sharifi et al., 2013). Several classes of drugs are indicated to hypertension. However, there has been an increase in use of herbal medicines in the last decades, which has encouraged studies of herbal products (Palhares et al., 2015).

Alpinia zerumbet (Family Zingiberaceae), known popularly as "colonia" in Northeast Brazil, where it used in folk medicine, predominantly to treatment of hypertension and anxiety (Santos et al, 2011a; Lahlou et al., 2003). Studies have shown that essential oil of $A$. zerumbet (EOAz) has pharmacological effects; in particular, it lowers blood pressure by means of vascular smooth muscle relaxation (Pinto et al., 2009; Santos et al., 2011a; Lahlou et al., 2003), antioxidant (Elzaawely et al., 2007), anxiolytic (De Araújo et al., 2009) and fungistatic (Lima et al., 1993) activities.

Considering that it is of great interest to explore the medicinal value of EOAz with regard to cardiovascular activities, and that this study can also serve as a support for the realization of future clinical trials, its constituents were separated into three fractions, hexane (HFEOAz), chloroform (CFEOAz), and methanol (MFEOAz) fractions, to better understand their pharmacological effects. In fact, the effect of these fractions on vascular function has not yet been reported. Thus, the purpose of this study was to characterize the components of the EOAz and its fractions and to determine their vasorelaxant and antihypertensive effects.

\section{MATERIALS AND METHODS \\ Plant material, extraction and chromatographic analysis}

A. zerumbet leaves were collected in November 2009, in Maranguape County, Ceará, Brazil. Botanical identification was determined in Prisco Bezerra Herbarium of School of Agronomy, Federal University of Ceará, where voucher specimen has been deposited under No. 50312. EOAz was extracted by hydrodistillation in Clevenger-type glass apparatus. Aliquot of oil was chromatographed in silica gel column and eluted with hexane, followed by chloroform and methanol. Crude oil and fractions were analyzed by gas chromatography coupled with mass spectrometry (GC-MS) and flame ionization detection (GC-FID) according to method described (Cavalcanti et al., 2012). GC-MS analysis was carried out on a Shimadzu QP5050 instrument equipped with non-polar OV-5 fused silica capillary column, while GC-FID analysis was carried out on a Shimadzu GC 2010 Plus instrument provided with non-polar CP-Sil-8 fused silica capillary column. Main constituents were confirmed by $1 \mathrm{H}$-nuclear magnetic resonance spectroscopy (1H-NMR).

\section{Animals and experiments}

Male Wistar rats weighing 200-250g (5060 days old) were used for in vitro experiments, and those weighing 250-330 g were used for in vivo experiments. Animals were kept under a 12 h-12 h light/dark cycle and allowed free access to food and water. Procedures were performed in accordance with the Animal Ethics Committee of Federal University of Ceará, Brazil, under registration No. 18/2011. There were two experimental phases: in vitro study to determine the vasorelaxant effect of EOAz and fractions in isolated aortic rings, and in vivo study to determine the effect of fractions on blood pressure measured by indirect tail cuff method in rats subjected to chronic hypertension by inhibition of nitric oxide.

\section{In vitro experiments: studies on isolated rat thoracic aorta}

Rats were sacrificed by cervical dislocation followed by exsanguination. Thoracic aorta was removed, cleaned of adherent connective tissue and cut into rings (3-4 $\mathrm{mm}$ in length). Two stainless-steel stirrups were passed through the lumen of each ring. One stirrup was connected to an isometric force transducer (Force Transducer, MLT0201, Panlab, Spain) to measure tension in the vessels. Rings were placed in a $10 \mathrm{~mL}$ organ chamber containing Krebs solution, gassed with $95 \% \mathrm{O}_{2}$ and $5 \% \mathrm{CO}_{2}$ and maintained at $37^{\circ} \mathrm{C}$ and $\mathrm{pH}$ 7.4. Composition of Krebs solution was as follows (mmol/L): $\mathrm{NaCl}, 118.0 ; \mathrm{KCl}, 4.7 ; \mathrm{KH}_{2} \mathrm{PO}_{4}$, 1.2; $\mathrm{MgSO}_{4} .7 \mathrm{H}_{2} \mathrm{O}, 1.2 ; \mathrm{NaHCO}_{3}, 15.0 ; \mathrm{CaCl}_{2}, 2.5$ and glucose, 5.5 (Hipólito et al., 2011). Aortic rings were stretched until they reached a resting tension of 10 millinewtons $(\mathrm{mN})$. They were then allowed to equilibrate for 60 minutes, during which time, bath solution was changed every 15-20 min. Endothelial integrity was assessed by degree of relaxation caused by acetylcholine $(10 \mu \mathrm{mol} / \mathrm{L})$ in presence of contractile tone induced by phenylephrine (1 $\mu \mathrm{mol} / \mathrm{L})$. After 60 minutes equilibration period, aortic rings were exposed to $\mathrm{KCl}(80 \mathrm{mmol} / \mathrm{L})$ (EstradaSoto et al., 2010). Steady tension was evoked by phenylephrine $(1 \mu \mathrm{mol} / \mathrm{L})$ (Chen et al., 2009), and EOAz and fractions were added cumulatively $(0.1$ $3,000 \mu \mathrm{g} / \mathrm{mL}$ ). 


\section{In vivo experiments: effects of the fractions and EOAz on arterial pressure}

Hypertension was induced in rats by administration of L-NAME $(30 \mathrm{mg} / \mathrm{kg}$ ) dissolved in drinking water for 60 days. First 30 days represented the induction phase of hypertension and was called pre-treatment. On the $31^{\text {st }}$ day, the rats were already hypertensive, and treatments studied were started and maintained for 30 days, corresponding to the treatment phase. Animals were randomly allocated into seven groups: negative control $(0.5 \mathrm{~mL}$ distilled water; $\mathrm{n}=9$ ), positive control (30 $\mathrm{mg} / \mathrm{kg}$ captopril; $n=11), \operatorname{EOAz}(n=8), \operatorname{HFEOAz}(n=9), \operatorname{CFEOAz}(n=8)$, MFEOAz $(\mathrm{n}=8)$, all at $100 \mathrm{mg} / \mathrm{kg}$, diluted in $0.5 \mathrm{~mL}$ distilled water.

EOAz and fractions dosages were determined from pre-clinical toxicology studies (Cunha, 2012). The dose of EOAz used in this protocol was assessed from acute and chronic toxicity studies in mice, where the dose at which adverse events were not observed was $200 \mathrm{mg} /$ $\mathrm{kg}$. For conversion of the dose of drug used in mice to the equivalent dose in rats the following formula was applied: Equivalent dose in rats = Drug dose at which adverse events were not observed in the animal $(\mathrm{mg} / \mathrm{kg}) \times\left(K_{m}\right.$ factor mouse $) /\left(K_{m}\right.$ factor rat $)$. In the formula, $K_{m}$ factor mouse is $3, K_{m}$ factor rat is 6 , and the dose calculations were $100 \mathrm{mg} / \mathrm{kg}$ for OEAz and fractions (HFEOAz, CFEOAz, MFEOAz) (Reagan-Shaw et al., 2008).

Treatments were by intragastric administration, at the same time (8:00 AM), for 30 days until 60th day. Measurements (blood pressure and heart rate) were recorded at pre-treatment every 6 days and in treatment phase every 3 days by tail cuff plethysmography method (IITC Life Science, model 229, Woodland Hills, CA).

Before measurements, conscious rats were restrained for 5-10 minutes in a warm chamber in a quiet room and conditioned to numerous cuff inflation-deflation cycles by a trained operator. Heart rate (HR), systolic (SAP), diastolic (DAP) and mean arterial (MAP) pressure were measured, the mean of three measurements was recorded. To evaluate overall antihypertensive effect of treatments used in this study, area under the curve (AUC) of SAP versus time was calculated by the trapezoidal method. Were determined the rate of systolic arterial pressure decline $(\mathrm{mmHg} /$ day) during treatment phase, which was obtained by following formula: Rate of SAP decline $=[\operatorname{SAP}($ day 30$)-\operatorname{SAP}($ day 60$)] / 30$ days.

\section{Solutions and drugs}

Following drugs and reagents were used in the in vitro studies: phenylephrine hydrochloride, acetylcholine hydrochloride, potassium chloride; diluents included Tween-80 and Krebs solution
$\left(\mathrm{NaCl}, \mathrm{KCl}, \mathrm{KH}_{2} \mathrm{PO}_{4}, \mathrm{MgSO}_{4} \cdot 7 \mathrm{H}_{2} \mathrm{O}, \mathrm{NaHCO}_{3}\right.$, $\mathrm{CaCl}_{2}$, glucose). All substances were from SigmaAldrich, St. Louis, MO, USA. EOAz and fractions were prepared as stock solutions in Tween 80 and sonicated; bath concentration of Tween 80 did not exceed $0.01 \%$. Concentration of Tween 80 did not exceed $0.5 \%$, which was shown to have no effect per se on the basal tonus of preparations or on the agonist-mediated contraction or relaxation (Hipólito et al., 2011; Lima-Accioly et al., 2006). For in vivo experiments, EOAz, fractions and captopril were diluted in distilled water and sonicated. Solutions were prepared fresh on the day of experiments.

\section{Data and statistical analysis}

In vascular reactivity studies, vasorelaxant response of EOAz and fractions was expressed as percentage relaxation of phenylephrine contraction. Concentration-response curves were constructed using non-linear regression according to the following sigmoidal equation: $y=a+(b-a) /\left[1+10^{(\log E C 50-x)]}\right.$, where $y$ is the response (relaxation or contraction), $x$ is the logarithm of concentration, $\mathrm{EC}_{50}$ is the concentration required to achieve a half-maximal response, a and $b$ correspond to the minimum and maximum response values, respectively. Two pharmacological parameters were determined from the concentrationresponse curves: $\mathrm{EC}_{50}$ and $\mathrm{E}_{\max }$, the maximal effect of test substance. Data were expressed as mean and standard error of mean (SEM) of at least 8 experiments performed on preparations obtained from different animals. Comparisons between five groups, concerning the $\mathrm{EC}_{50}$ and $\mathrm{E}_{\max }$ values, were carried out using one-way analysis of variance (ANOVA) followed by Tukey's multiple comparison test to compare all pairs of groups.

For evaluating the antihypertensive effect of MFEOAz, variables were analyzed by KolmogorovSmirnov test for normal distribution of data. As such criteria were met in all analyses, mean and standard deviation (SD) were calculated for descriptive statistics, and parametric tests for analytical statistics. Comparisons between groups, concerning the temporal progression of SAP, DAP, MAP, HR, rate of SAP decline and AUC of SAP, were performed using one-way analysis of variance (ANOVA) followed by Tukey's multiple comparison test. Significance level was set at $0.05(5 \%)$ so that values of $\mathrm{P}<0.05$ were considered significant. GraphPad Prism ${ }^{\circledR}$ version 5.00 for Windows ${ }^{\circledR}$ was used to perform statistical procedures and graphs.

\section{RESULTS \\ Chemical composition of $A$. zerumbet essential oil and its fractions \\ GC-MS and GC-FID analysis of EOAz and fractions obtained by chromatographic separation}


permitted identification of thirty-two constituents, including 25 monoterpenes, 6 sesquiterpenes and one alkane. Crude oil contained chiefly 1,8-cineol $(22.40 \%), p$-cymene $(18.91 \%)$ and terpinen-4ol $(17.32 \%)$. HFEOAz was composed mainly of $p$-cymene $(31.46 \%), y$-terpinene $(19.02 \%)$ and sabinene $(16.69 \%)$, whereas 1,8-cineol $(58.92 \%)$ and terpinen-4-ol (35.53\%) were the most abundant compounds in CFEOAz. MFEOAz also showed 1,8 -cineol $(27.81 \%)$ and terpinen-4-ol $(57.35 \%)$ as the major components, but its contents were virtually in reverse proportions. Some minor compounds such as camphene, phelandrene, $p$-menth-2-en1 -ol and $\gamma$-cadinene could be detected only after chromatographic fractionation (Table 1).

\begin{abstract}
Effect of the EOAz and fractions on rat aortic rings pre-contracted with phenylephrine

Were obtained concentration-response curves of relaxation induced by different concentrations (0.01 to $3,000 \mu \mathrm{g} / \mathrm{mL})$ of EOAz, fractions and control (Tween 80). Were used preparations of aortic rings with intact endothelium pre-contracted with phenylephrine $(1 \mu \mathrm{mol} / \mathrm{l})$. EOAz and fractions caused concentration-dependent relaxation, and at the highest concentration $(3,000$ $\mu \mathrm{g} / \mathrm{ml}$ ), the fractions caused full relaxation of aortic rings. Contractile response was more markedly induced by HFEOAz, primarily at doses of 10 , 30 and $100 \mu \mathrm{g} / \mathrm{mL}$. This effect also occurred to a lesser extent with EOAz, CFEOAz and MFEOAz (Figure 1). $E_{\max }$ values of EOAz and fractions were significantly higher $\left({ }^{* *} \mathrm{P}<0.001\right)$ than control (Figure
\end{abstract}

TABLE 1. Components of EOAz, HFEOAz, CFEOAz and MFEOAz.

\begin{tabular}{|c|c|c|c|c|c|}
\hline Component & $\mathrm{IK}^{*}$ & EOAZ (\%) & HFEOAz (\%) & CFEOAz (\%) & MFEOAz (\%) \\
\hline$\alpha$-Thujene & 929 & 3.84 & 6.85 & - & - \\
\hline$\alpha$-Pinene & 939 & 2.12 & 3.53 & - & - \\
\hline Unknown 1 & 948 & - & 0.13 & - & - \\
\hline Camphene & 958 & - & 0.45 & - & - \\
\hline Sabinene & 979 & 9.90 & 16.69 & - & - \\
\hline$\beta$-Pinene & 986 & 3.60 & 6.54 & - & - \\
\hline$\beta$-Myrcene & 993 & 0.80 & 0.88 & - & - \\
\hline Decane & 1003 & - & 0.08 & - & - \\
\hline Phelandrene & 1014 & - & 0.18 & - & - \\
\hline$\alpha$-Terpinene & 1024 & 2.50 & 2.61 & - & - \\
\hline p-Cymene & 1032 & 18.91 & 31.46 & - & - \\
\hline Limonene & 1036 & 2.42 & 4.66 & - & - \\
\hline 1,8-Cineol & 1040 & 22.40 & 2.66 & 58.92 & 27.81 \\
\hline$y$-Terpinene & 1064 & 11.42 & 19.02 & - & - \\
\hline Unknown 2 & 1079 & - & - & 0.08 & - \\
\hline 4-Thujanol & 1080 & - & - & 0.37 & 1.64 \\
\hline$\alpha$-Terpinolene & 1090 & 1.18 & 1.25 & - & - \\
\hline Linalool & 1106 & 1.04 & - & 0.36 & 1.48 \\
\hline cis- $\beta$-Dihydro-terpineol & 1110 & - & - & - & 2.14 \\
\hline cis-p-Menth-2-en-1-ol & 1135 & - & - & 0.31 & 1.77 \\
\hline trans- $p$-Menth-2-en-1-ol & 1153 & - & - & 0.12 & 1.47 \\
\hline trans-Dihydro- $\alpha$-terpineol & 1180 & - & - & - & 0.29 \\
\hline Borneol & 1182 & - & - & - & 0.31 \\
\hline Terpinen-4-ol & 1189 & 17.32 & - & 35.53 & 57.35 \\
\hline p-Cymen-8-ol & 1197 & - & - & - & 0.08 \\
\hline$\alpha$-Terpineol & 1203 & 0.78 & - & 0.71 & 3.82 \\
\hline trans-Piperitol & 1219 & - & - & - & 0.38 \\
\hline Bornyl acetate & 1290 & - & - & 0.49 & 0.05 \\
\hline trans- $\beta$-Caryophyllene & 1421 & 1.11 & 2.47 & - & - \\
\hline$\alpha$-Caryophyllene & 1458 & - & 0.29 & - & - \\
\hline$y$-Cadinene & 1513 & - & 0.25 & - & - \\
\hline Caryophyllene oxide & 1584 & 0.66 & - & 2.87 & 1.00 \\
\hline Humulene epoxide II & 1614 & - & - & 0.22 & - \\
\hline
\end{tabular}

*IK:Kovats retention indices calculated from a homologous series of $n$-alkanes $\left(C_{7}-C_{30}\right)$ analyzed on a CP-Sil-8 column. 
1). There were no significant differences between $E O A z$ and fractions (Table 2). $E_{50}$ of MFEOAz was significantly lower than the EOAz $(P<0.001)$, CFEOAz $(P<0.01)$ and HFEOAz $(P<0.001) . E_{50}$ of CFEOAz was significantly lower $(P<0.05)$ than the HFEOAz (Table 2).

In vivo experiments: effects of EOAz and fractions on arterial pressure

SAP, DAP, MAP and HR were measured throughout the experiment. Figure 2 shows the induction phase of hypertension by chronic administration of L-NAME. Progressive increase in blood pressure was observed in the six groups. HR varied little in induction phase (Figure 2).

From the 31st day, which marked the start of treatments, control group maintained upward pressure values. In the captopril group, antihypertensive action has already started on day 3 of treatment (study day 33) and remained stable until the end of the study (day 60). However, in the HFEOAz and MFEOAz groups, antihypertensive effect was seen from day 6 (36 days of study) and day 9 (39 days of study) in the EOAz and CFEOAz groups. During treatment phase, antihypertensive effect of EOAz and fractions was lower than the captopril, except at the end of study, mostly on the 60th day, at which time the antihypertensive activity of both compounds was similar. In relation to the temporal behavior of HR in the treatment groups, similar temporal pattern was observed in the six groups characterized by specific alterations, demonstrating that there was little interference of treatment with HR (Figures 3, 4, 5, 6).

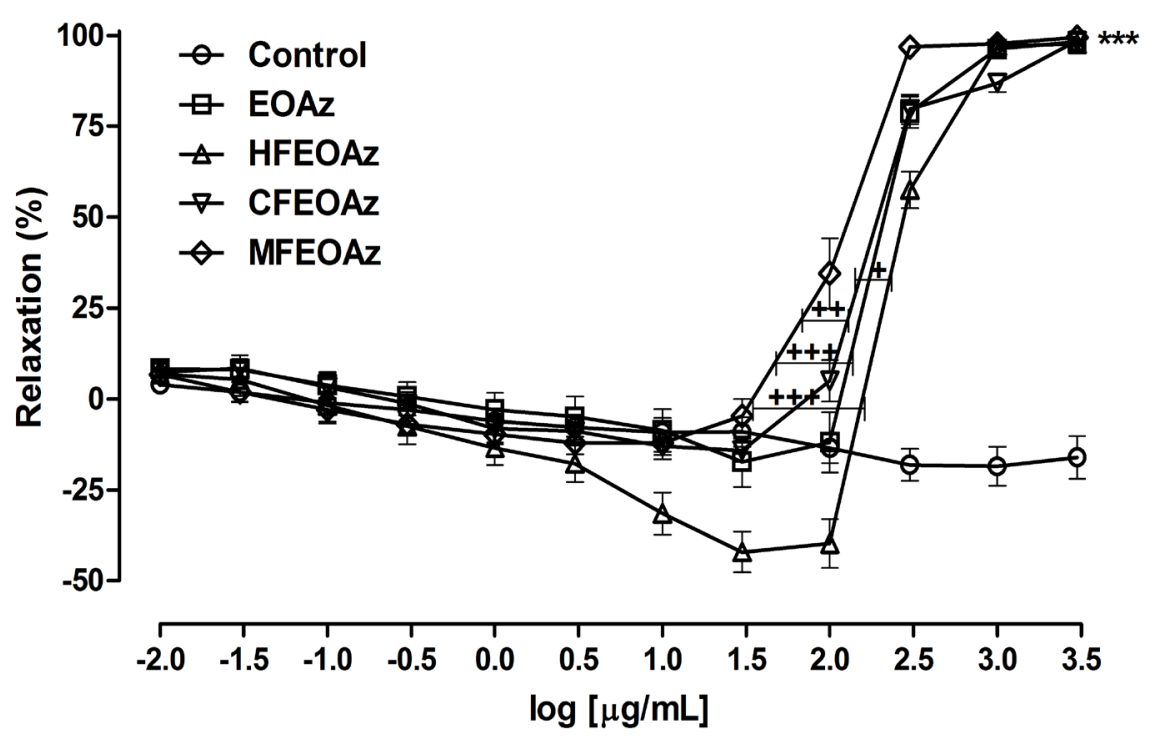

FIGURE 1. Vasorelaxant response induced by EOAz, HFEOAz, CFEOAz and MFEOAz in rat aortic rings precontracted with phenylephrine $(1 \mu \mathrm{mol} / \mathrm{l})$. Vasodilator effect was evaluated on endothelium-intact preparations. Data expressed as mean \pm SEM of 8 experiments performed on preparations obtained from different animals. $E_{50}$ of MFEOAz was significantly lower than the EOAz $\left({ }^{++} \mathrm{P}<0.001\right)$, CFEOAz $\left({ }^{++} \mathrm{P}<0.001\right)$ and HFEOAz $\left({ }^{++} \mathrm{P}<0.01\right)$, and $\mathrm{EC}_{50}$ of CFEOAz was significantly lower $(+\mathrm{P}<0.05)$ than the FHOEAz. $\mathrm{E}_{\max }$ values of EOAz, HFEOAz, CFEOAz and MFEOAz were significantly higher $\left({ }^{* * *} \mathrm{P}<0.001\right)$ than the control.

TABLE 2. $E_{50}$ and $E_{\text {max }}$ related the vasorelaxant effect of EOAz and fractions on endothelium-intact rat aortic rings pre-contracted with phenylephrine. Data correspond at measurements carried in 8 experiments in each group performed on preparations obtained from different animals.

\begin{tabular}{lcccc}
\hline \multirow{2}{*}{ Substance } & \multicolumn{2}{c}{$\mathrm{EC}_{50}(\mu \mathrm{g} / \mathrm{ml})$} & \multicolumn{2}{c}{$\mathrm{E}_{\max }(\%)$} \\
\cline { 2 - 5 } & Value & $95 \% \mathrm{Cl}$ & Mean & 1.18 \\
EOAz & 378.01 & $218.72-653.31$ & 98.22 & 1.61 \\
HFEOAz & 581.59 & $301.02-1123.69$ & 97.59 & 1.05 \\
CFEOAz & $300.34 \S$ & $194.40-464.01$ & 98.51 & 0.54 \\
MFEOAz & $150.45^{\circ \neq}$ & $105.48-214.58$ & 99.46 & 0 \\
\hline
\end{tabular}

95\% Cl: 95\%confidence interval; SEM: standard error of the mean. $\S \mathrm{P}=0.0352$ compared to $\mathrm{HFEOAz}$; $\mathrm{P}<0.0001 \mathrm{compared}$ to $\mathrm{HFEOAz}$; $\dagger \mathrm{P}=0.0003$ compared to $\mathrm{EOAz} ; \mathrm{P}=0.0025$ compared to CFEOAz. 
A

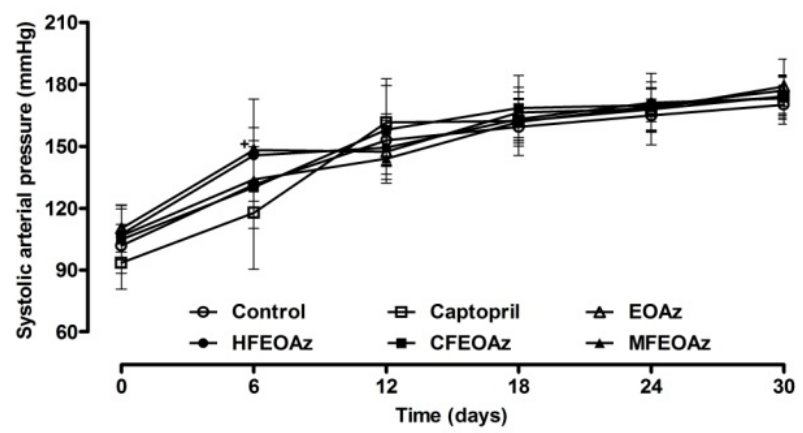

C

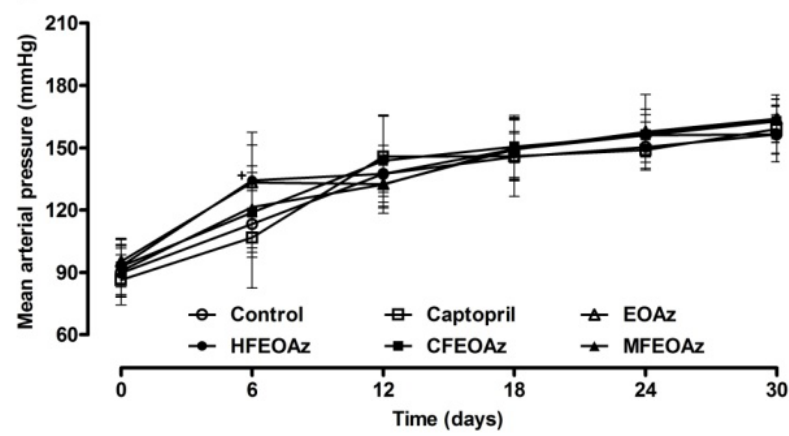

B

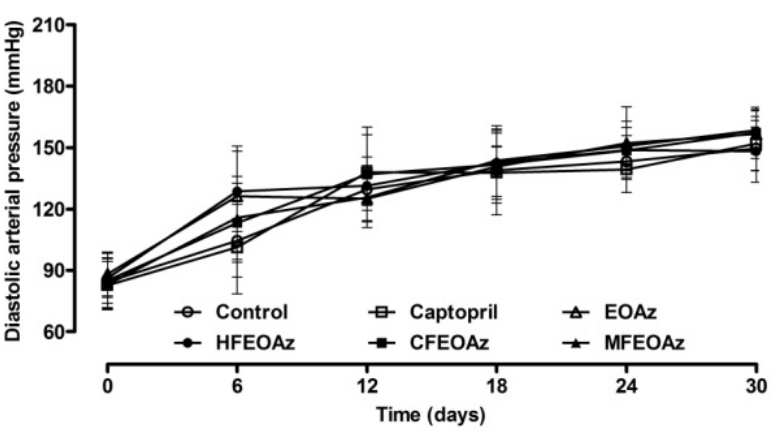

D

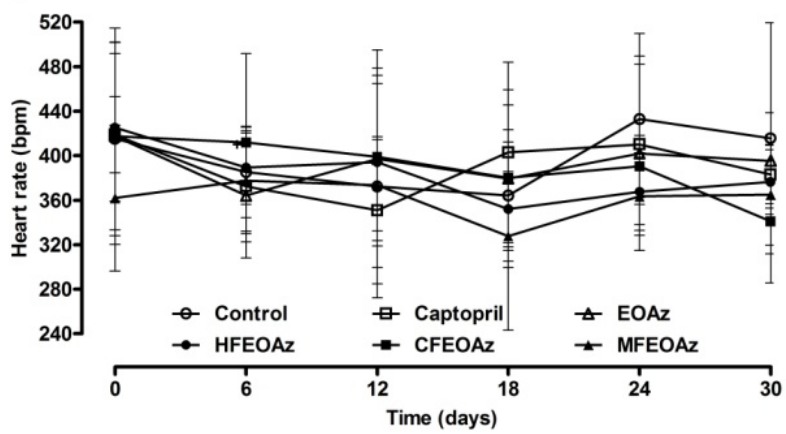

FIGURE 2. Temporal progression of systolic (A), diastolic (B), mean arterial pressure (C) and heart rate (D) in the groups control $(n=9)$, captopril $(n=11)$, EOAz $(n=8), \operatorname{HFEOAz}(n=9), \operatorname{CFEOAz}(n=8)$ and MFEOAz $(n=8)$, during the first 30 days, which corresponded to hypertension induction phase. Data represent mean and standard deviation of measurements performed at each time point. $+P<0.05$ compared to the captopril group (ANOVA followed by Tukey's multiple comparison test).

A

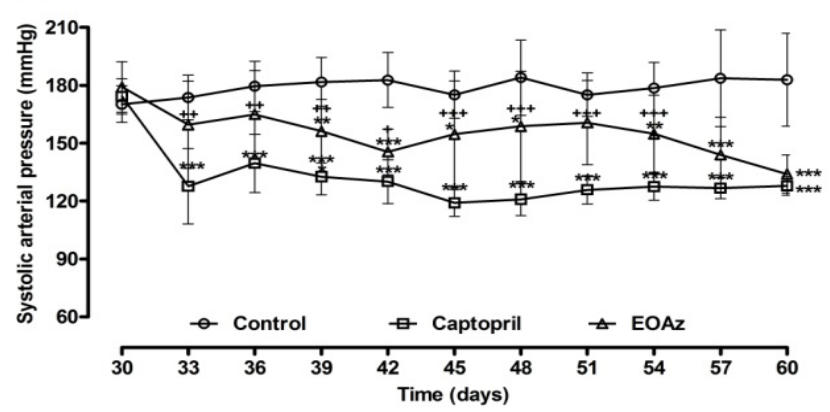

C

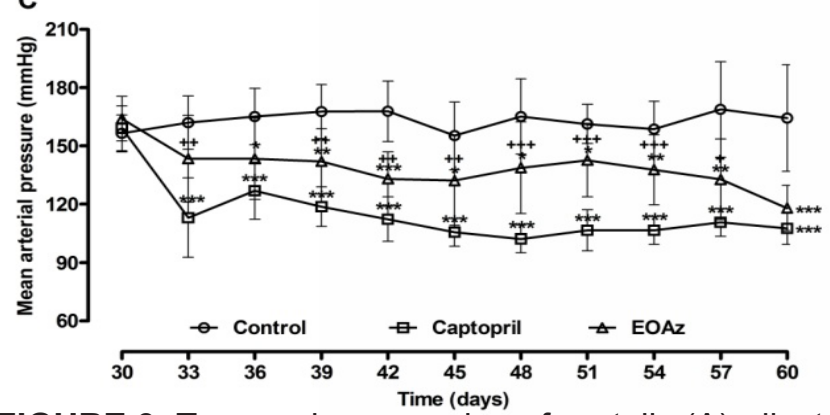

B

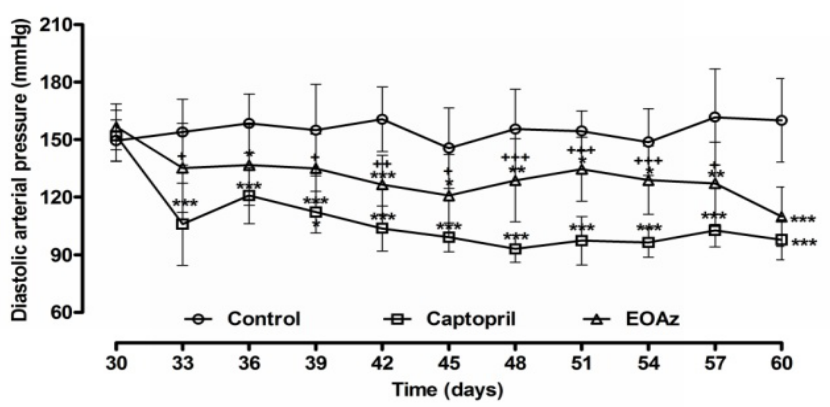

D

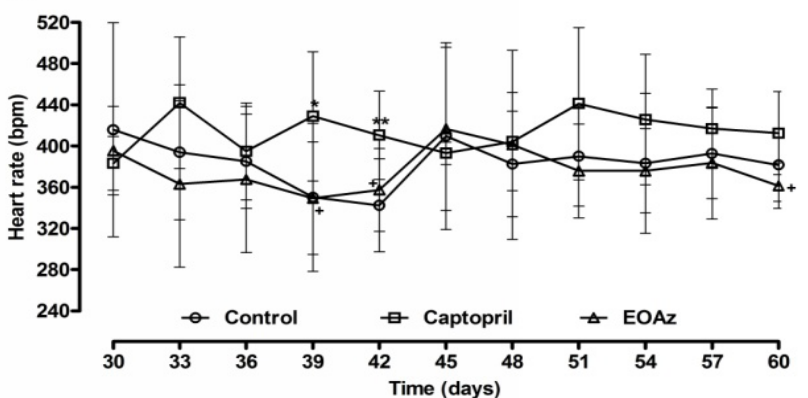

FIGURE 3. Temporal progression of systolic (A), diastolic (B), mean arterial pressure (C) and heart rate (D) in the groups control $(n=9)$, captopril $(n=11)$ and EOAz $(n=8)$. Hypertension was induced and sustained by chronic administration of L-NAME for 60 days. First 30 days corresponded to the hypertension induction phase, and last 30 days to the treatment phase. At each time point, data represent mean and standard deviation of measurements. ${ }^{* * *} \mathrm{P}<0.001,{ }^{* *} \mathrm{P}<0.01,{ }^{*} \mathrm{P}<0.05$ compared to control group; ${ }^{+++} \mathrm{P}<0.001,{ }^{++} \mathrm{P}<0.01,{ }^{+} \mathrm{P}<0.05$ compared to captopril group (ANOVA followed by Tukey's multiple comparison test). 
A

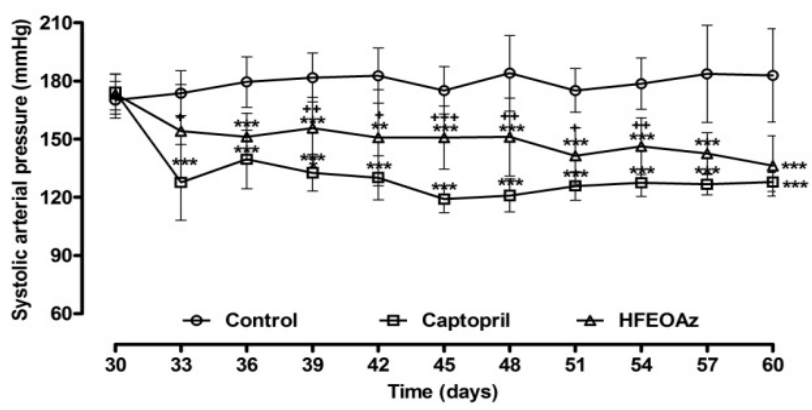

C

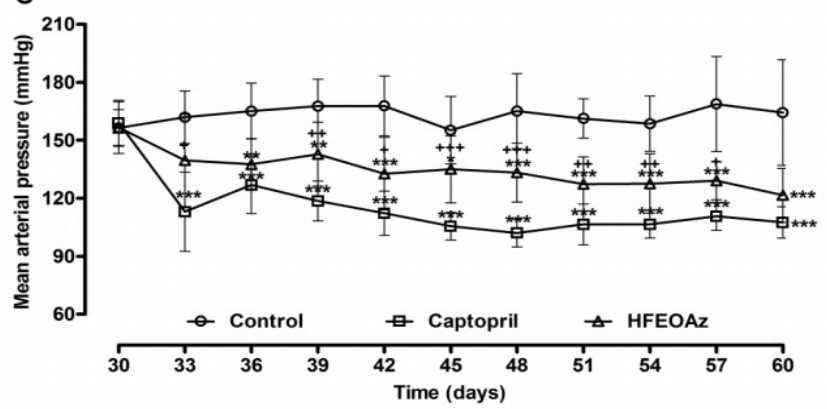

B

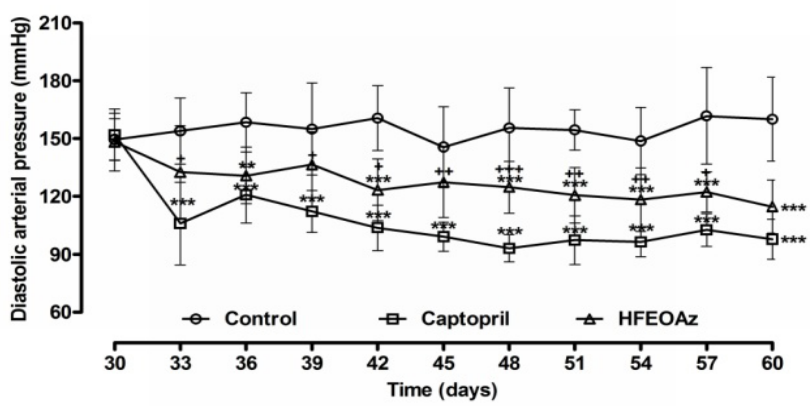

D

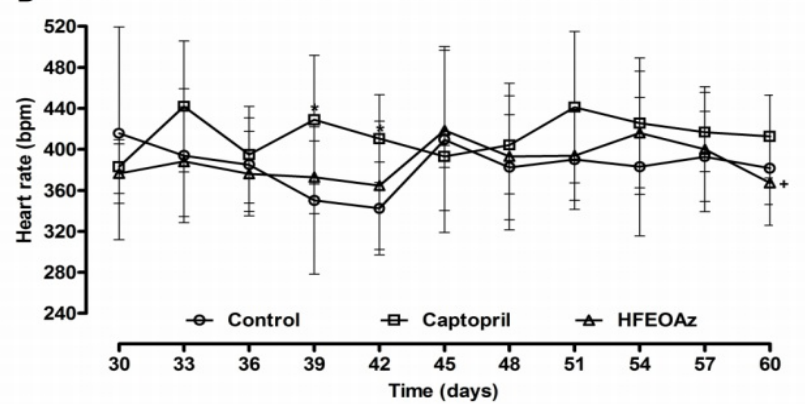

FIGURE 4. Temporal progression of systolic (A), diastolic (B), mean arterial pressure (C) and heart rate (D) in the groups control $(n=9)$, captopril $(n=11)$ and HFEOAz $(n=9)$. Hypertension was induced and sustained by chronic administration of L-NAME for 60 days. The first 30 days corresponded to the hypertension induction phase, and the last 30 days to the treatment phase. At each time point, data represent the mean and standard deviation. ${ }^{* * *} \mathrm{P}<0.001,{ }^{* *} \mathrm{P}<0.01,{ }^{*} \mathrm{P}<0.05$ compared to control group; ${ }^{+++} \mathrm{P}<0.001,{ }^{++} \mathrm{P}<0.01,{ }^{+} \mathrm{P}<0.05$ compared to captopril group (ANOVA followed by Tukey's multiple comparison test).

A

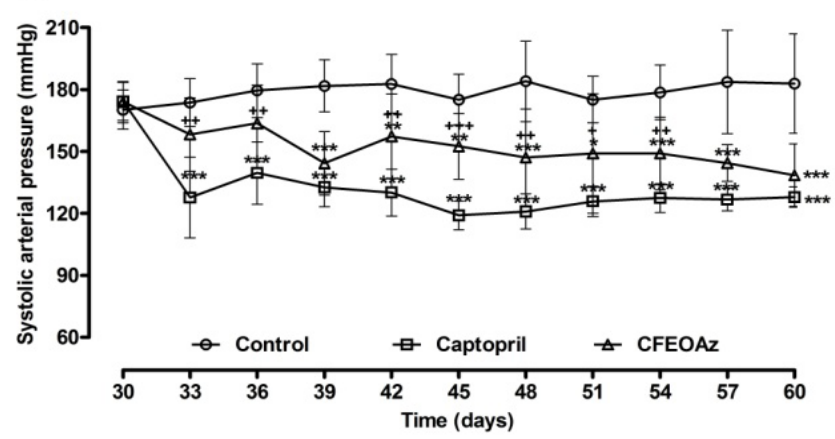

C

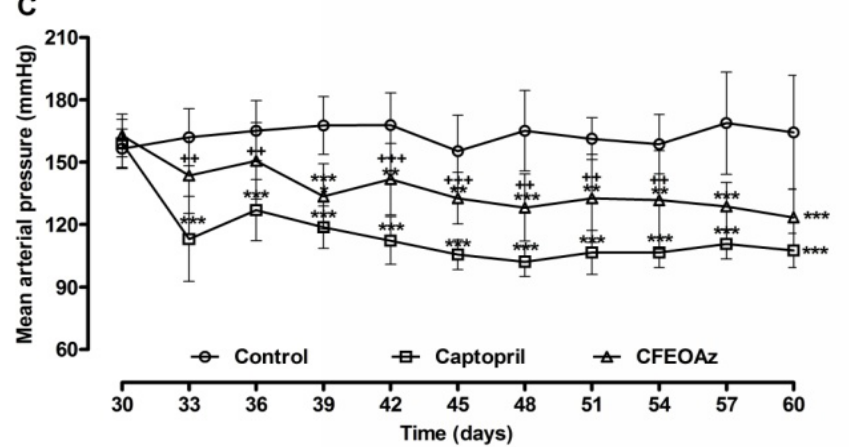

B
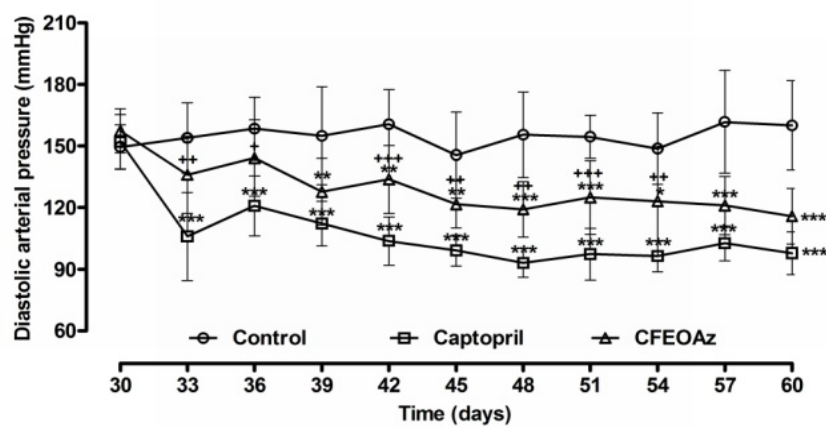

D

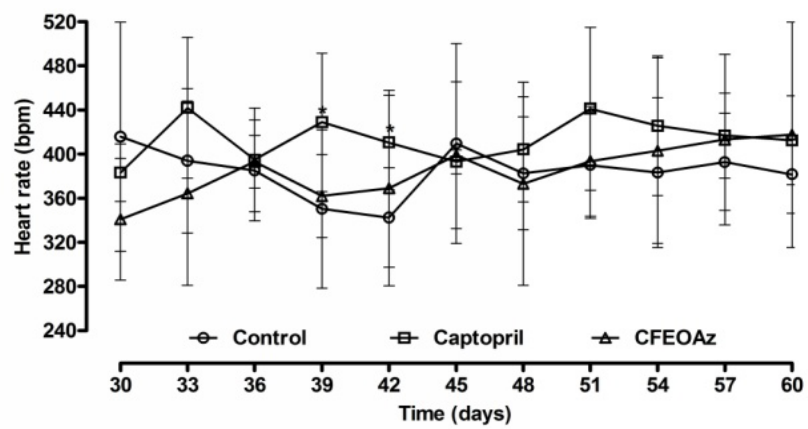

FIGURE 5. Temporal progression of systolic $(A)$, diastolic $(B)$, mean arterial pressure $(C)$ and heart rate $(D)$ in the groups control $(n=9)$, captopril $(n=11)$ and CFEOAz $(n=8)$. Hypertension was induced and sustained by chronic administration of L-NAME for 60 days. The first 30 days corresponded to the hypertension induction phase, and the last 30 days to treatment phase. At each time point, data represent the mean and standard deviation. ${ }^{* *} \mathrm{P}<0.001,{ }^{* *} \mathrm{P}<0.01,{ }^{*} \mathrm{P}<0.05$ compared to control group; ${ }^{++} \mathrm{P}<0.001,{ }^{++} \mathrm{P}<0.01,{ }^{+} \mathrm{P}<0.05$ compared to captopril group (ANOVA followed by Tukey's multiple comparison test). 
A

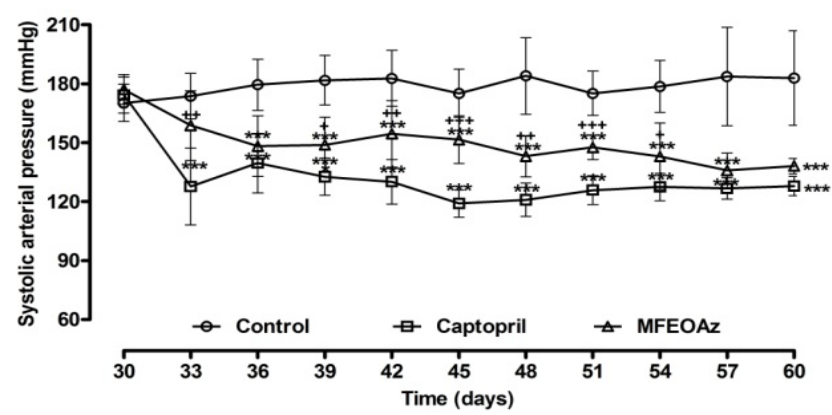

C

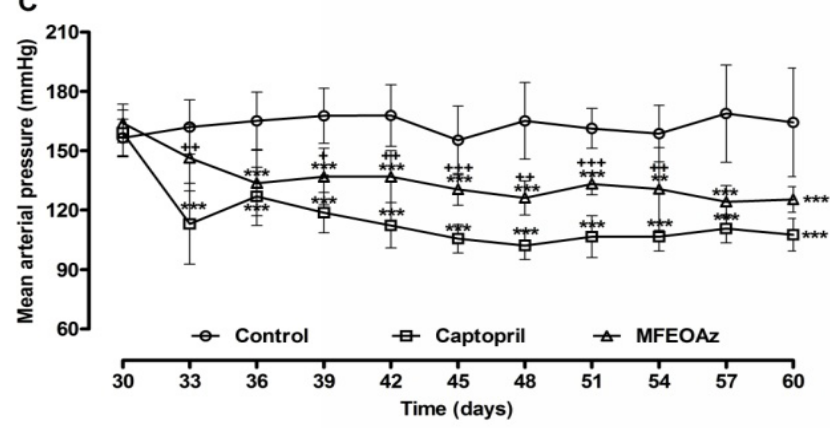

B

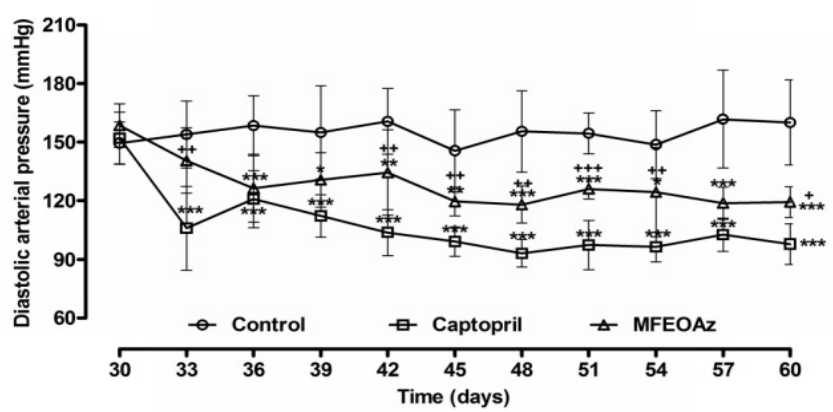

D

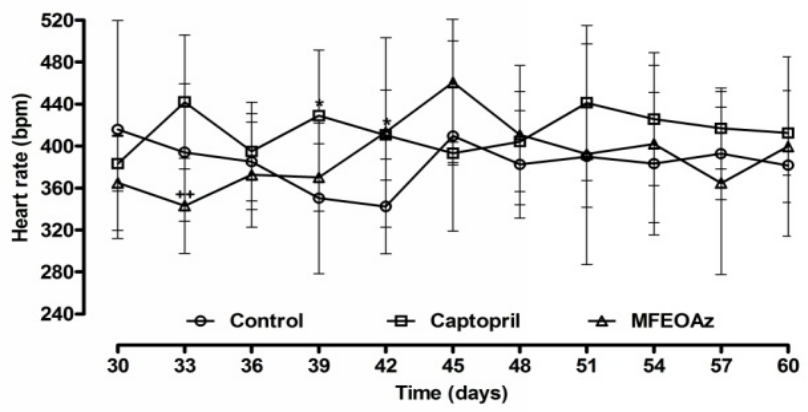

FIGURE 6. Temporal progression of systolic (A), diastolic (B), mean arterial pressure (C) and heart rate (D) in the groups control $(n=9)$, captopril $(n=11)$ and MFEOAz $(n=8)$. Hypertension was induced and sustained by chronic administration of L-NAME for 60 days. The first 30 days corresponded to hypertension induction phase, and the last 30 days to treatment phase. At each time point, data represent the mean and standard deviation. ${ }^{* * *} \mathrm{P}<0.001,{ }^{* *} \mathrm{P}<0.01,{ }^{*} \mathrm{P}<0.05$ compared to control group; ${ }^{+++} \mathrm{P}<0.001,{ }^{++} \mathrm{P}<0.01,+\mathrm{P}<0.05$ compared to captopril group (ANOVA followed by Tukey's multiple comparison test).

A

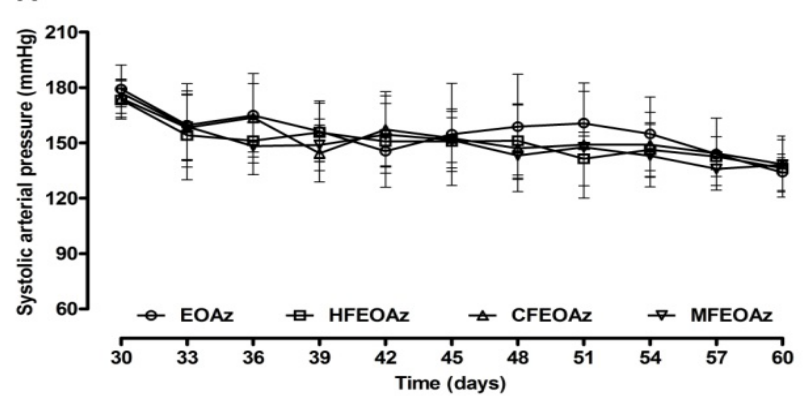

C

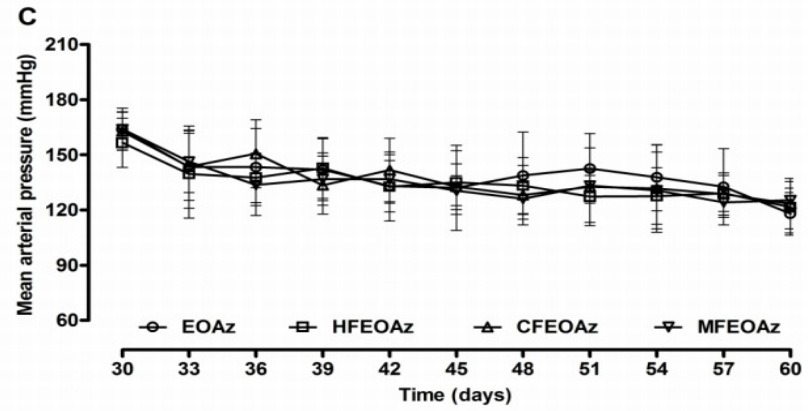

B

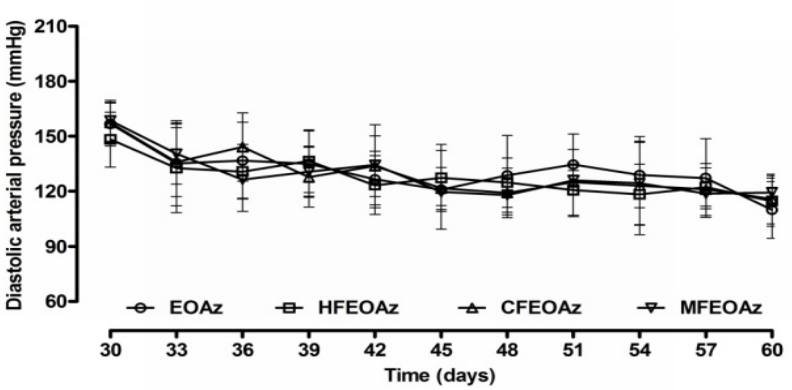

D

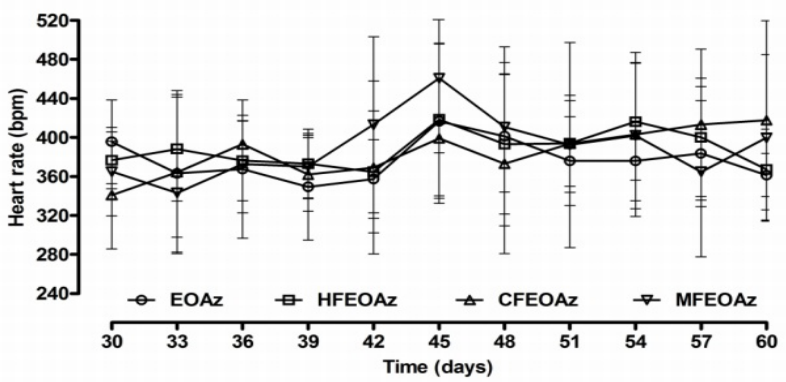

FIGURE 7. Temporal progression of systolic (A), diastolic (B), mean (C) arterial pressure, and heart rate (D) in groups EOAz, HFEOAz, CFEOAz and MFEOAz. Hypertension was induced and sustained by chronic administration of L-NAME for 60 days. The first 30 days corresponded to hypertension induction phase, and the last 30 days to treatment phase. At each time point, data represent mean and standard deviation. Were no statistically significant differences between groups at any time point (ANOVA followed by Tukey's multiple comparison test). 
Comparing the antihypertensive effects of $E O A z$ and fractions in the treatment phase, there was similar temporal pattern, so that there was no statistically significant difference between them at any of the times evaluated. This fact was also observed in relation to HR (Figure 7).

Overall antihypertensive effect was evaluated in six treatment groups by determining of area under the curve of time versus SBP (Figure 8). Reduction rate of PAS, in turn, reflects the speed at which PAS decreased over the treatment phase. Overall antihypertensive effect provided by EOAz and fractions was higher than the observed in negative control and less than the observed in group treated with captopril (A and B). EOAz, fractions and captopril induced a significant increase in rate of decay of SBP compared to the negative control (C). FIGURE 8. Global evaluation of antihypertensive effect verified in the groups control $(n=9)$, captopril $(n=11), \operatorname{EOAz}(n=8), \operatorname{HFEOAz}(n=9), \operatorname{CFEOAz}(n=8)$ and MFEOAz $(n=8)$. Area under the curve $(A)$ of systolic arterial pressure (SAP) versus time denotes the overall antihypertensive effect of treatments. It was calculated according to the trapezoidal method (B). Reduction rate of SAP (C) denotes velocity of SAP decrease over in treatment phase. Data represent mean (A) and standard deviation $(B, C) .{ }^{* * *} P<0.001,{ }^{* *} P<0.01$ compared to control group; ${ }^{++} \mathrm{P}<0.001,++\mathrm{P}<0.01,+\mathrm{P}<0.05$ compared to captopril group (ANOVA followed by Tukey's multiple comparison test).

\section{DISCUSSION}

In this research, we did not use isolated components, since our main interest was to use the knowledge gained to further studies in humans using phytotherapeutics and not isolated substances.
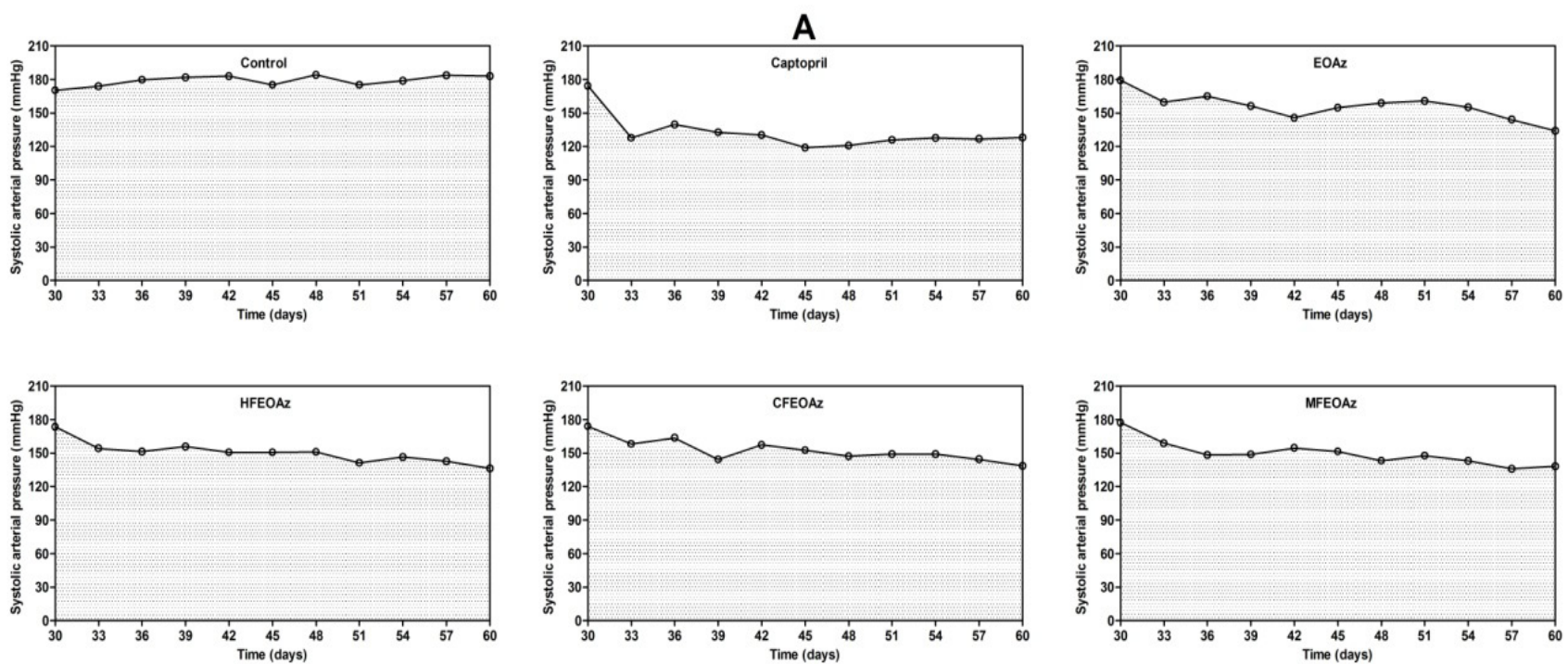

B

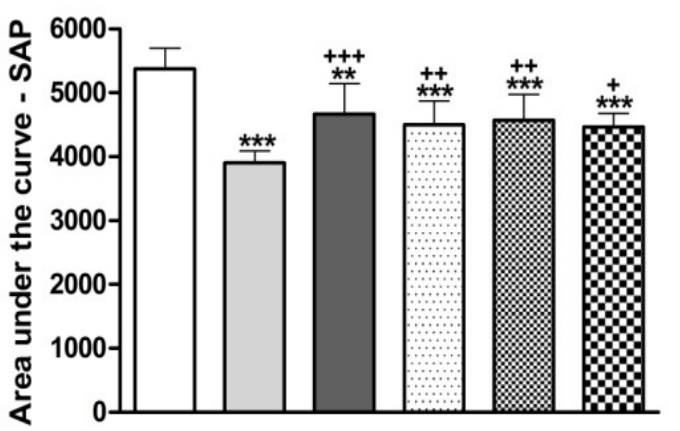

C

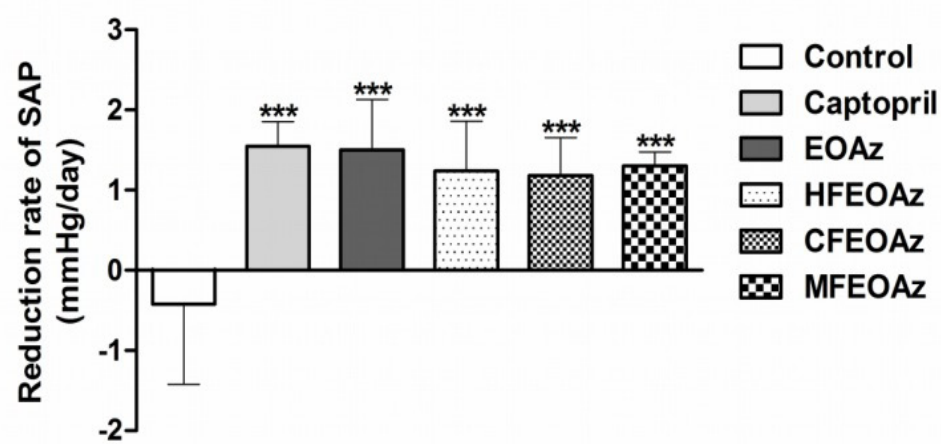

FIGURE 8. Global evaluation of antihypertensive effect verified in the groups control $(n=9)$, captopril $(n=11)$, EOAz $(n=8), \operatorname{HFEOAz}(n=9), \operatorname{CFEOAz}(n=8)$ and MFEOAz $(n=8)$. Area under the curve $(A)$ of systolic arterial pressure (SAP) versus time denotes the overall antihypertensive effect of treatments. It was calculated according to the trapezoidal method $(B)$. Reduction rate of SAP (C) denotes velocity of SAP decrease over in treatment phase. Data represent mean $(A)$ and standard deviation $(B, C) .{ }^{* *} P<0.001$, ${ }^{* *} P<0.01$ compared to control group; $+++P<0.001$, $++P<0.01,+P<0.05$ compared to captopril group (ANOVA followed by Tukey's multiple comparison test). 
Evaluation of herbal purification to isolate or even identify chemical constituents is not necessary. Pharmacologically active ingredients can be analyzed by focusing on one or more ingredients purportedly responsible for the activity of plant, by studying a compound makes up a considerable part of total composition or by chromatographic profile of total ingredients (Brasil, 2008).

The investigation of naturally occurring agents acting on the cardiovascular system, especially those that reduce blood pressure is a growing area, with potential for the discovery of molecules that can be used to develop new antihypertensive drugs (Mahmood et al., 2010, Tirapelli et al., 2010).

All major components of EOAz and fractions were monoterpenes. Monoterpenes are secondary metabolites of plants. They have various pharmacological properties including antifungal, antibacterial, antioxidant, anticancer, anti-spasmodic, hypotensive, and vasorelaxant (Santos et al., 2011b). Compounds tested must act by different mechanisms of action. In fact, monoterpene alcohols, aldehydes, ethers, and hydrocarbons show effects on the cardiovascular system via vasorelaxation, decreased heart rate or hypotension, among others (Lima et al., 2012).

In the initial in vitro evaluation of EOAz and fractions, it was found that these substances cause relaxation of rat aortic preparations with intact endothelium pre-contracted with phenylephrine in a dose-dependent manner, so that at the higher concentration $(3,000 \mu \mathrm{g} / \mathrm{ml})$ there was complete relaxation of aortic rings with the tested substances.

Existence of a biphasic effect, equivalent to a slight vasoconstriction, driven by HFEOAz at doses of 10,30 and $100 \mu \mathrm{g} / \mathrm{mL}$ was observed. At high doses, there was no biphasic effect, but significant vasodilation in aortic preparations with intact endothelium pre-contracted with phenylephrine. No previous studies with EOAz have reported occurrence of biphasic effect. In relation to fractions, no studies have examined this aspect, and thus, this is the first study we know of to use hexane, chloroform and methanol fractions of EOAz. Biphasic effect has been identified in other studies with herbal products that evaluated vasodilator activity of natural substances extracted from plants. Regarding this effect, the authors mentioned that it was due to a transient increase in $\mathrm{Ca}^{2+}$ influx from the extracellular medium (Chiwororo \& Ojewole, 2008; Zhang et al., 2010).

Analysis of the vasorelaxant effect of EOAz and fractions in aorta rings pre-contracted with phenylephrine, it was concluded that the substance with lowest $\mathrm{EC}_{50}$ was MFEOAz $(150.45 \mu \mathrm{g} / \mathrm{ml})$. The major components in this fraction were 1,8 -cineol
(27.81\%) and terpinen-4-ol (57.35\%). The second substance with a lower $\mathrm{EC}_{50}$ was CFEOAz (300.34 $\mu \mathrm{g} / \mathrm{ml}$ ), where the major components were 1,8 -cineol $(58.92 \%)$ and terpinen-4-ol (35.53\%). It is noteworthy that this fraction contained 1,8-cineol in greater amounts than the terpinen-4-ol, unlike what was found in MFEOAz.

$E_{50}$ of EOAz was $378.01 \mu \mathrm{g} / \mathrm{ml}$, showing by phytochemical analysis two major components, 1,8-cineol $(22.40 \%)$ and terpinen-4-ol (17.32\%) in smaller proportions than those observed in MFEOAz and CFEOAz. Although HFEOAz had vasodilator activity, it also showed a biphasic effect and greater $E_{50}(581.59 \mu \mathrm{g} / \mathrm{ml})$. HFEOAz had as the major components sabinene $(16.69 \%)$, p-cymene $(31.46 \%)$ and $y$-terpinene $(19.02 \%)$, rather than terpinen-4-ol and 1,8-cineol.

In most chromatographic analyses of essential oils derived from $A$. zerumbet used in other studies, terpinen-4-ol and 1,8-cineol were the most abundant components (Lahlou et al., 2002a; Lahlou et al., 2002b; Lahlou et al., 2003; Pinto et al., 2009; Barcelos et al., 2010; Santos et al., 2011a). Previous studies have shown that the essential oil of $A$. zerumbet has vasorelaxant activity in vitro and in vivo, and hypotensive action, and that this action is due to its major constituents, terpinen-4-ol and 1,8-cineol, when evaluated as a pure substance, because both showed hypotensive and vasodilator activity (Lahlou et al., 2002a; Lahlou et al., 2002b; Lahlou et al., 2003).

Considering the findings in the literature and because MFEOAz had the lowest $\mathrm{EC}_{50}$ and showed the terpinen-4-ol and 1,8-cineolas the main constituents, we infer that its vasodilator effect was probably due to the presence of these constituents, particularly for terpinen-4-ol, since CFEOAz had the second lowest $\mathrm{EC}_{50}$ and had more 1,8-cineol than terpinen-4-ol.

In this study, we used tail plethysmography to determine indirect blood pressure, a method that measures SAP in rodents. The advantages of this method is that it can be easily used in many animals, allows for monitoring blood pressure for long periods of time, and is a validated and widely accepted method for experiments of this type (Irvine et al., 1997; Fritz \& Rinaldi, 2008). The more precisely parameter analyzed is SAP, but DAP, MAP and HR were also determined. Other studies with substances from plants have also analyzed all parameters obtained by this method (Fritz \& Rinaldi, 2008; Vergara-Galicia, 2008).

Animals were subjected to chronic hypertension by inhibiting nitric oxide synthesis, which was performed by administration of L-NAME. This model of hypertension is widely accepted and validated (Baylis et al., 1992; Fazan et al., 2001; 
Ribeiro \& Muscará, 2001; Rang et al., 2012). Were found that the group treated with L-NAME had a statistically significant increase in PAS when compared to baseline time (day 0 ) and the control group, treated withdrinking water. There were no major changes in heart rate and body mass of the animals treated with L-NAME.

Results showed that a single administration by gavage of EOAz, HFEOAz, CFEOAz and MFEOAz as well as the positive control with captopril was able to significantly reduce blood pressure in rats subjected to chronic hypertension model by inhibition of nitric oxide when compared to the control treated with distilled water. Overall, the experiments performed here showed that hypotensive effect was also observed in other pre-clinical studies that evaluated the essential oil of $A$. zerumbet (Barcelos et al., 2010; Santos et al., 2011a). It has been found that hypotension in rats occurs independently of the operational presence of the sympathetic nervous system, suggesting that EOAz is a direct vasodilator (Lahlou et al., 2002a; Lahlou et al., 2002b).

In conclusion, the potency of the MFEOAz was higher than that of EOAz and other fractions. The antihypertensive effect of EOAz and fractions was similar, higher than the negative control and lower than that of captopril. We emphasize that more studies are needed to identify the mechanism of action of EOAz and its fractions.

\section{REFERENCES}

BARCELOS, F.F. et al. Phytochemistry and cardiovascular biological activity of the essential oil from leaves of Alpinia zerumbet (Pers.) B.L. Burtt\&R.M.Sm. in rats. Revista Brasileira de Plantas Medicinais, v.12, n.1, p.48-56, 2010.

BAYLIS, C.; et al., Chronic blockade of nitric oxide synthesis in the rat produces systemic hypertension and glomerular damage. The Journal of Clinical Investigation, v.90, n.1, p.278-281, 1992.

BRASIL. Ministério da Saúde. Características químicas, produção e controle de qualidade (CMC) para fitoterápicos. Instruções operacionais: Informações necessárias para a condução de ensaios clínicos com fitoterápicos, 6-7, 2008. Brasília: Ministério da Saúde, 2008. Disponível em: http://bvsms.saude.gov. br/bvs/publicacoes/fitoterapicos.pdf. Acesso em: 20 jan. 2015.

CAVALCANTI, B.C. et al. Genetic toxicology evaluation of essential oil of Alpinia zerumbet and its chemoprotective effects against $\mathrm{H}_{2} \mathrm{O}_{2}$-induced DNA damage in cultured human leukocytes. Food and Chemical Toxicology, v.50, n.11, p.4051-4061, 2012.

CHEN, G. et al. Endothelium-independent vasorelaxant effect of sodium ferulate on rat thoracic aorta. Life Sciences, v.84, n.3-4, p.81-88, 2009.

CHIWORORO, W.D.H.; OJEWOLE, J.A.O. Biphasic effect of Psidium guajava Linn. (Myrtaceae) leaf aqueous extract on rat isolated vascular smooth muscles. Journal of smooth muscle research, v.44, n.6, p.217-229, 2008.

CUNHA, G.H. Efeito farmacológico das frações hexânica, clorofórmica e metanólica do óleo essencial da Alpinia zerumbet na reatividade vascular in vitro e nos parâmetros cardiovasculares in vivo. 2012. 223p. Tese (Doutorado - Área de Concentração Farmacologia) - Departamento de Fisiologia e Farmacologia, Universidade Federal do Ceará, Fortaleza.

DE ARAÚJO, F.Y. et al. Central nervous system effects of the essential oil of the leaves of Alpinia zerumbet in mice. The Journal of Pharmacy and Pharmacology, v.61, n.11, p.1521-1527, 2009.

ELZAAWELY, A.A.; et al., Essential oils, kava pyrones and phenolic compounds from leaves and rhizomes of Alpinia zerumbet (Pers.) B.L.Burtt. \& R.M. Sm. and their antioxidant activity. Food Chemistray, v.103, n.2, p.486-494, 2007.

ESTRADA-SOTO, S. et al. Vasorelaxant effect of Valeriana edulis ssp. procera (Valerianaceae) and its mode of action as calcium channel blocker. The Journal of Pharmacy and Pharmacology, v.62, n.9, p.1167-1174, 2010.

FAZAN JR, R.; et al., Modelos de hipertensão arterial. Revista Brasileira de Hipertensão, v.8, n.1, p.19-29, 2001.

FRITZ, M.; RINALDI, G. Blood pressure measurement with the tail-cuff method in Wistar and spontaneously hypertensive rats: influence of adrenergic- and nitric oxide-mediated vasomotion. Journal of Pharmacological and Toxicological Methods, v.58, n.3, p.215-221, 2008.

HIPÓLITO, U.V. et al. The semi-synthetic kaurane ent16a-methoxykauran-19-oic acid induces vascular relaxation and hypotension in rats. European Journal of pharmacology, v.660, n.2-3, p.402-410, 2011.

IRVINE, R.J.; et al., The influence of restraint on blood pressure in the rat. Journal of Pharmacological and Toxicological Methods, v.38, n.3, p.157-162, 1997.

LAHLOU, M.S. et al. Cardiovascular effects of 1,8-cineole, a terpenoide oxide present in many plant essential oils, in normotensive rats. Canadian Journal of Physiology and Pharmacology, v.80, n.12, p.1125-1131, 2002a.

LAHLOU, M.S. et al. Cardiovascular effects of the essential oil of Alpinia zerumbet leaves and its main constituent, terpinen-4-ol, in rats: role of the autonomic nervous system. Planta Medica, v.68, n.12, p.1097-1102, 2002b.

LAHLOU, S. et al. Antihypertensive effects of the essential oil of Alpinia zerumbet and its main constituent terpinen4-ol, in DOCA-salt hypertensive conscious rats. Fundamental and Clinical Pharmacology, v.17, n.3, p.323-330, 2003.

LIMA-ACCIOLY, P.M. et al. Essential oil of Croton nepetaefolius and its main constituent, 1,8-cineole, block excitability of rat sciatic nerve in vitro. Clinical and Experimental Pharmacology and Physiology, v.33, n.12, p.1158-1163, 2006.

LIMA, E.O. et al. In vitro antifungal activity of essential oils obtained from officinal plants against dermatophytes. Mycoses, v.36, n.9-10, p.333-336, 1993.

LIMA, T.C. et al. Structural relationships and vasorelaxant 
activity of monoterpenes. Daru, v.20, n.1, p.23, 2012.

MAHMOOD, Z.A. et al. Herbal treatment for cardiovascular disease the evidence based therapy. Pakistan Journal of Pharmaceutical Sciences, v.23, n.1, p.119-124, 2010.

PALHARES, R.M. et al. Medicinal plants recommended by the world health organization: DNA barcode identification associated with chemical analyses guarantees their quality. PLoS One, v.10, n.5, p.e0127866, 2015.

PINTO, N.V. et al. Endothelium-dependent vasorelaxant effects of the essential oil from aerial parts of Alpinia zerumbet and its main constituent 1,8-cineole in rats. Phytomedicine, v.16, n.12, p.1151-1155, 2009.

RANG, H.P. et al. Farmacologia. 7.ed. Rio de Janeiro: Elsevier, 2012. 742p.

REAGAN-SHAW, $S$; ; et al., Dose translation from animal to human studies revisited. FASEB Journal, v.22, n.3, p.659-661, 2007.

RIBEIRO, W.; MUSCARÁ, M.N. Características farmacocinéticas de antagonistas de cálcio, inibidores de ECA e antagonistas de angiotensina II em humanos. Revista Brasileira de Hipertensão, v.8, n.1, p.114-124, 2001.

SANTOS, B.A. et al. Cardiodepressive effect elicited by the essential oil of Alpinia speciosa is related to
L-type $\mathrm{Ca}^{2+}$ current blockade. Phytomedicine, v.18, n.7, p.539-543, 2011a.

SANTOS, M.R.V. et al. Cardiovascular effects of monoterpenes: a review. Brazilian Journal of Pharmacognosy, v.21, n.4, p.764-771, 2011b.

SHARIFI, N. et al. Discovery of new angiotensin converting enzyme (ACE) inhibitors from medicinal plants to treat hypertension using an in vitro assay. Daru, v.21, n.1, p.74, 2013.

TIRAPELLI, C.R. et al. Hypotensive action of naturally occurring diterpenes: a therapeutic promise for the treatment of hypertension. Fitoterapia, v.81, n.7, p.609-702, 2010.

VERGARA-GALICIA, J. et al. Antihypertensive and vasorelaxant activities of Laeliaautumnalis are mainly through calcium channel blockade. Vascular Pharmacology, v.49, n.1, p.26-31, 2008.

YANNOUTSOS, A. et al. Pathophysiology of hypertension: interactions between macro and microvascular alterations through endothelial dysfunction. Journal of Hypertension, v.32, n.2, p.216-224, 2014.

ZHANG, N. et al. Biphasic effects of sodium danshensu on vessel function in isolated rat aorta. Acta Pharmacologica Sinica, v.31, n.4, p.421-428, 2010. 